\title{
The Influence of Situational Clues against the Background of Crowdfunding Product Picture on the Investment Intention-The Mediating Effect of the Mental Imagery
}

\author{
Min Hou \\ School of Business Administration \\ Zhejiang Gongshang University \\ Hangzhou, Zhejiang, China \\ min_hou@126.com
}

\author{
Guoyu Song* \\ School of Business Administration \\ Zhejiang Gongshang University \\ Hangzhou, Zhejiang, China \\ 1821463812@qq.com
}

\author{
Chunmei Gu \\ School of Business Administration \\ Zhejiang Gongshang University \\ Hangzhou, Zhejiang, China \\ gucm58@163.com
}

\begin{abstract}
Based on the theory of mental imagery, this study aims to explore the impact of situational clues of the background of crowdfunding product picture on investment intention to purchase. The experiment uses 2 (product type: search product vs. experience product) $\times 2$ (whether the product picture background has relevant situational clues: yes vs. no) inter-group experimental design. The data collected by questionnaire star is used to analyze the reliability and validity of the data obtained by the scale. The theoretical model is empirically tested. The results of the study show that when the product shows the picture with situational clues without relevant background to the product, the situational clues with relevant background of the product can enhance the investment intention; when the product type of the crowdfunding product is the experience product, compared with products, the situational clues with relevant background of the product will produce a higher the degree of mental imagery. The mental imagery is the intermediary mechanism of the influence of situational clues on the purchase intention. When the product has a product-related context, it can produce a higher degree of mental imagery, thereby increasing investment intention.
\end{abstract}

Keywords-Mental imagery; Crowdfunding; Product type; Investment intention

\section{INTRODUCTION}

In recent years, a new online shopping model emerged product crowdfunding, crowdfunding products have not been evaluated or experienced by consumers after buying, so in the crowdfunding, effective product display not only attracts consumers to visit crowdfunding sites, but also facilitates consumer purchase or investment decisions in the absence of a direct product experience. In an online environment where consumers cannot personally inspect a product before purchasing, product display plays a key role in triggering emotional and cognitive responses, which in turn affects the shopping experience and results.

Empirical studies have found that the way of products presentation will affect the online consumer shopping experience. Empirical research find support for such views. For example, different background colors will have different effects on consumers' product evaluation and behavior [1]; With the latest advances in technology, more and more online apparel retailers are beginning to adopt innovative visualization tools (eg, zoom, 3D views and videos) to meet consumer demand for sensory product experiences; models are better presented in a networked environment and express product quality, and thus increasing consumer perception of touch; research has found that complex picture are more effective and appealing to the various emotional and cognitive experiences [2]. However, the current related research mainly focuses on the technical means of displaying products or the position or size of the products in the picture. There are few researches on the situational clues for the background of the pictures in the product display, whether they will be consumed under the different background of the product picture. In the context of the picture of the product, consumers will have different ways of processing the psychological information of the products, and bring different experience and consumption of virtual products, and then affect the investor's investment intention.

In crowdfunding, when tea garden are used as a background and solid colors are used as a background to display tea, which one do you choose, maybe someone chooses the former, some choose the latter, why? Looking back at existing product research findings, past research has focused on exploring the individual differences of consumers and the impact of product factors on investment or purchase intention. 
This article will examine whether the situational clues in the background of product picture have an impact on crowdfunding products and the specific impact mechanisms. This paper believes that the situational clues of different backgrounds of crowdfunding products will influence the consumer's shopping experience to influence the final decision, and mental imagery will play a mediating role. Specifically, the mental imagery refers to the individual's mental process of imagining through the stimulation of pictures, specific textual descriptions or mental indicators such as things that have not yet been experienced. The generation of such an image will produce a certain final decision. Impact. In addition, the product type is an important variable in marketing, with a variety of attributes, people will define different types of products according to the attributes of the product, mainly divided into experience products and search products. Studies have shown that consumers have different perceptions of consumers about different types of products, and thus consumers' purchase or investment decisions have an impact. According to the review, this study is based on the perspective of mental theory. It mainly studies several questions: How do the situational clues in the background of crowdfunding product display affect investors' investment intention? How do investors change their mental imagerys when they are in different product types? Does the product types have an impact on consumers' investment intention in different scenarios? This research is the extension and application of the theory of mental imagery in consumer behavior, and provides a new idea for how to better display the crowdfunding products to investors or consumers in practice.

\section{LITERATURE REVIEW AND HYPOTHETICAL REASONING}

\section{A. Mental imagery}

The mental imagery is regarded as a kind of psychological activity that visualizes concepts or relationships. The mental imagery reflects the process of expressing feelings or perceptual experiences in the way of thought, emotion and memory in the individual's working memory [2]. Imagery may be multi-sensory because people can incorporate psychological picture into the auditory, visual, tactile, and gustatory stimuli, but the mental imagery can also involve a single visual sense. Visual imagery is the most important, followed by auditory imagery. Individuals can produce a kind of psychological process similar to imagination through image stimulation such as pictures. The mental imagery can process and integrate multiple sensory information (such as visual, tactile, smell, etc.), which is more conducive to generating memories, affecting consumer perceptions and attitudes. The mental imagery has a strong potential for interpretation. Even in the face of things that the individual has not experienced, there is no real feeling of stimulation, and the virtual personal experience can be experienced through the mental imagery [3]. Walters, Sparks, and Herington (2007) argue that mental imagery has two dimensions: elaboration and quality. Elaboration means the number of pictures that people are igniting in their mental imagerys. Quality refers to their vividness, clarity, strength, clarity and appeal. Walters et al. stated that specific pictures and captions of travel destinations help to improve the elaboration and quality of mental imagery [3].

\section{B. Situational clues and investment intention}

Having a vivid picture can stimulate the consumer's senses, allowing investors to experience the function and characteristics of the product in advance, thus affecting investors' investment intention. Guozhen Zhu and others found that by using models as a way of presentation, the quality of clothing can be better expressed, thereby increasing consumers' intention to purchase. When a product does not exist in the physical environment, people will evaluate the product based on their own imagination of the consumer experience [4]. Therefore, in online retailing, product picture (such as swimwear) on situational clues (such as beaches) related to the consumption background can evoke the consumer's mental imagery, thereby promoting the consumption perspective to wear the swimsuit, better experience and understanding of crowdfunding. The characteristics and attributes of the product, resulting in a purchase intention. In summary, this study proposes the hypothesis:

H1: When the product is displayed in a picture with a situational clues that has no relevant background to the product, the situational clues with relevant background of the product can enhance the investor's investment intention.

\section{Moderating effect of Product type}

Considering the display of crowdfunding products, we have to consider the differences in product types. Predecessors divide products into search products and experience products. Search products refer to products that consumers can obtain product information to determine product quality before purchase and use, such as mobile phones, cameras, etc.; experience products refer to consumers need to use after that, we can judge the quality of the products, such as wine, food, etc. For the experience product, in the Internet context, when consumers can't directly experience the product, they tend to process the information by imagining the use scene of the product in life or an environment, that is, the association between the product and the context clue. A higher degree of mental imagery, and ultimately the judgment and evaluation of the product [6]. In summary, this study proposes the hypothesis:

$\mathrm{H} 2$ : The product type has a moderating effect in the process of the impact of different situational clues on the degree of mental imagery. Under a situational clues that has relevant background to the product, the experience product will produce a higher degree of mental imagery than the search product consumer.

\section{Mediating effect of mental imagery}

We believe that in the context of the network, the degree of correlation between the product and the situational cues of background in the picture will trigger different levels of mental imagery processing. The mental imagery is a kind of psychological aspect of the perception of things, the abstract processing and description of the image of the human brain, and it is a psychological situation. The consumer's mental imagery includes all the consumer scenes in one's heart, all his/her fantasy and plans, inspiring the imagination and embarrassment of consumers. Consumers in the process of 
buying new products, before the purchase of the imagination can form a consumer scene in the mental imagery of consumers, in this case, consumers will be more inclined to buy product of a mental imagery or a scene. Consumers in the specific picture will produce a higher level of mental awakening, resulting in positive emotional and behavioral intentions [4]. In summary, this study proposes the hypothesis:
H3: The mental imagery plays a mediating role between the situational clues and the investment intention. When a product has a situational clues that has relevant background, it can produce a higher degree of mental imagery, thereby increasing the investment intention.

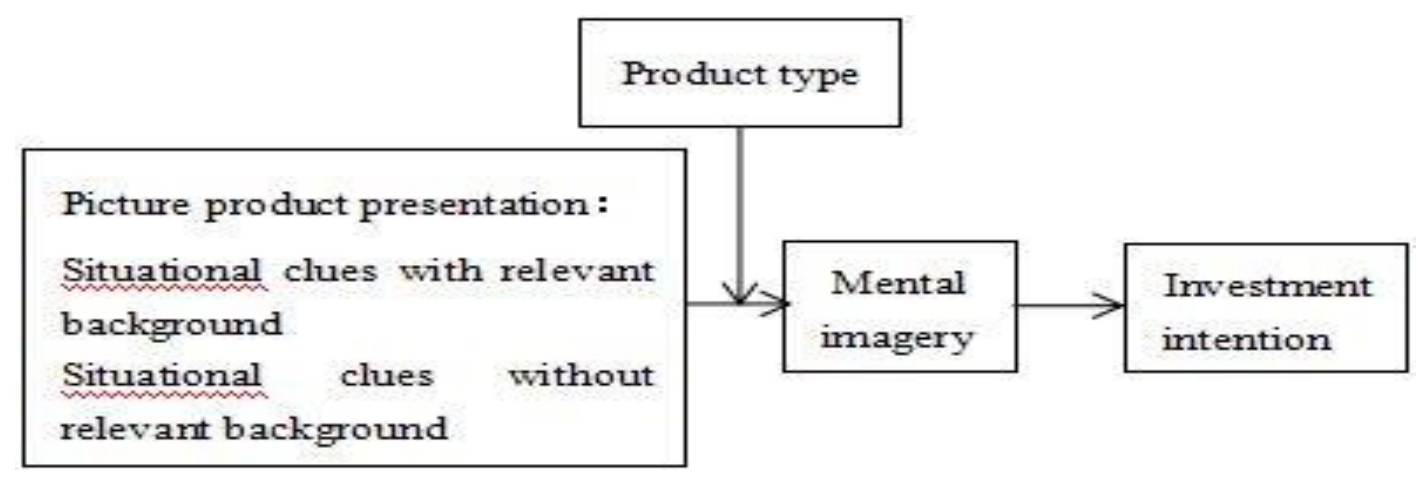

Fig. 1 Research model

\section{RESEARCH METHODS}

The main purpose of the experiment is to which way between background and product clues and no background scene clues can produce more higher degree of mental imagery (H1), and whether situational cues play a moderating role in the process of influencing the image of investors in different product types (H2). Whether the image of the mental imagery plays a mediating role between the situational clues and the investment intention, that is, whether it can produce a higher degree of mental imagery when the consumer has a context related to the product, thereby increasing the investment intention.

\section{A. Stimulus materials}

According to the classification method of the products of the predecessors, the products are divided into search products and experience products. The experimental subjects mainly extracted 16 different products and descriptions from a crowdfunding website, and 34 subjects who were collected on the Internet to judge the product type, and finally selected liquor and mosquito killing lamps as experimental materials for the study. The products used in the experiment were all unfamiliar brands, which excluded the participants from affecting the experimental results according to the brand of the product. All the picture of the advertisements are properly processed by Photoshop to meet the requirements of the experimental control. One is the situational clues of the background of the picture related to the liquor or the mosquito killer. The background is processed by the Photoshop software as pure white, that is, without relevant background.

\section{B. Experimental design}

A total of 220 participants were collected from the questionnaire by using this questionnaire, and finally 213 subjects completed the experiment. The experiment used 2 (product type: search products vs experience products) $\times 2$ (situational clues with whether the product has a relevant background: no vs. yes) inter-group experimental design. All the participants were divided into four groups, and the specific grouping results were: search products - 52 participants with situational clues with relevant background; search products 52 participants with situational clues with no relevant background; experience products - 55 participants with situational clues with relevant background; experience products - 54 participants with situational clues without relevant background.

This experiment uses the form of questionnaire survey to obtain data. The questionnaire is based on the Likert 7-point scale, which includes the mental imagery, investment intention and basic personal information. The measurement of the mental imagery mainly refers to the scale used by Yoo and Kim (2014) to measure the mental imagery. The measurement of the investion intention mainly refers to the scale used by Lin Shuang and others to measure the intention to purchase, and the appropriate adjustment is made. Finally fill in the demographic variables.

\section{Reliability and validity analysis}

In order to make the experiment effective, it is necessary to test the reliability and validity of the experimental data. In the analysis, each variable has many measurement components, so the Cronbach' $\alpha$ coefficient is used for the reliability test. All variables included in this study had Cronbach' $\alpha$ greater than 0.8 . The data showed that the Cronbach' $\alpha$ coefficient of the mental scale was 0.935 , and the Cronbach' $\alpha$ coefficient of the investment intention scale was 0.868 . Therefore, both variables have good reliability. In the validity analysis, it is first necessary to use KMO and Bartlett sample measures to test whether the data is suitable for factor analysis. Finally, the data 
shows that the KMO of the mental scale is 0951, which is greater than 0.5 , and the $\mathrm{KMO}$ of the investment intention scale is 0.820, which is also greater than 0.5; And the Barlett spherical test reached a significant level $(\mathrm{p}<0.000)$, indicating that it is suitable for factor analysis. Then the factor load is calculated by factor analysis to be greater than 0.7 , indicating that the two variables have good validity.

\section{Data Analysis and Discussion}

First of all, this paper believes that when the product is displayed in a picture with situational clues that have no relevant background to the product, the situational clues with relevant background of the product can enhance the investor's investment intention. We used one-way analysis of variance to support hypotheses. The experimental data showed that the impact of investment intention in the product picture presentation was significantly different $(\mathrm{F}=35.503, \mathrm{p}<0.05)$, and the effect of the picture of the situational clues with relevant background of the product on the investment intention $(M=4.83)$ is significantly higher than the picture of the situational clues with no relevant background of the product $(M=4.17)$, thus showing the product compared to the picture of the situational clues without relevant background of the product, and the situational clues with relevant backgrounds with product can increase investors' investment intention. Therefore, $\mathrm{H} 1$ is effectively supported.

The effect of regulation of product types was examined by using analysis of variance. The experimental data showed (Table 1) that the main effect of the scene clues in the background of the product image was significant $(F=71.401$, $\mathrm{p}<0.05)$, but the main effect of the product type was not significant $(\mathrm{F}=0.143, \mathrm{p}>0.05)$, the product The situational cues of the type and product picture background produced significant interaction effects on the heart $(\mathrm{F}=28.915, \mathrm{p}<0.05)$. Since the interaction effect is significant, further simple effect testing is required. It was found that when the product type was an experience product, the subject would have a higher degree of visual cues than the situational cues without related background when viewing the pictures of the situational cues with relevant background. Explain that the product type plays a regulatory role in the influence of the situational clue on the degree of occurrence of the mental imagery. Specifically, in the case where the product type is an experience product, the situational clues with relevant backgrounds will produce a higher degree of mentality than the situational clues without relevant background $(\mathrm{M}=5.20, \mathrm{M}$ no $=4.05, \mathrm{p}<0.05)$. Therefore, $\mathrm{H} 2$ is effectively supported.

TABLE I THE INTERACTION OF PRODUCT TYPE AND PRODUCT SITUATIONAL CLUES ON MENTAL IMAGERY

\begin{tabular}{llccc}
\hline Variables & df & $\begin{array}{c}\text { Mean } \\
\text { Square }\end{array}$ & F & Sig. \\
\hline Degree of correlation & 1 & 26.273 & 71.401 & 0.000 \\
\hline Product type & 1 & 0.052 & 0.143 & 0.706 \\
\hline Degree of correlation×product type & 1 & 10.640 & 28.915 & 0.000 \\
\hline error & & & & \\
\hline
\end{tabular}

TABLE II CORRELATION ANALYSIS OF MENTAL IMAGERY AND INVESTMENT INTENTION

\begin{tabular}{|c|c|c|c|}
\hline & & $\begin{array}{l}\text { Investment } \\
\text { intention }\end{array}$ & $\begin{array}{l}\text { Mental } \\
\text { imagery }\end{array}$ \\
\hline \multirow{3}{*}{$\begin{array}{l}\text { Investment } \\
\text { intention }\end{array}$} & Pearson Correlation & 1 & $0.773 * *$ \\
\hline & Sig. (2-tailed) & & 0.000 \\
\hline & $\mathrm{N}$ & 213 & 213 \\
\hline \multirow[t]{3}{*}{ Mental imagery } & Pearson Correlation & $0.773 * *$ & 1 \\
\hline & Sig. (2-tailed) & 0.000 & \\
\hline & $\mathrm{N}$ & 213 & 213 \\
\hline
\end{tabular}

This paper believes that the mental imagery plays a mediating role between the situational clues and the investment intention. When there are situational clues with relevant background, it can produce a higher degree of mental imagery, thus increasing the investment intention. The mediation of the mental imagery is tested by regression. Firstly, the situational clues on the background of the picture are regressed to the mental imagery. The data test results show that the regression coefficient is $c=0.380, p=0.000<0.05$, so the main effect of the independent variable on the dependent variable is significant, and then the situational background of the picture background is checked. The regression coefficient a, the data shows $\mathrm{a}=0.486, \mathrm{p}=0.000<0.05$, so the effect of the independent variable on the mediator variable is significant. Finally, the regression coefficients of $\mathrm{b}$ and $\mathrm{c}$ are tested. The data shows $\mathrm{b}=0.771, \mathrm{p}=0.000<0.05$, but $\mathrm{c}$ is not significant $(\mathrm{p}=0.922>0.05)$. The situational clues in the background of the picture are in the 
process of investment intention. To the role of intermediary. Further assume that 3 is supported.

\section{RESEARCH CONCLUSIONS AND MARKETING INSPIRATION}

The conclusions of this paper mainly include the following three aspects: First, the situational clues in the product picture presentation will affect the investor's investment intention. In the product presentation process, relative to the situational clues that have no relevant background to the product, the situational clues related to the product will allow investors or consumers to invest in the product. Second, the product type has a moderating effect on the situational clues with or without relevant background and mental imagery. That is to say, when the product type is the experience product, the investor will have a higher degree of mental imagery than the search product. Third, the mental imagery plays a mediating role between the situational clues and the investment intention, and solves the mechanism of action on the purchase intention in different picture backgrounds.

The marketing inspiration of this research: First, in order to better present their products, fundraisers can let investors understand the characteristics and attributes of products through the presentation of product picture, so fundraisers should display picture according to the consumption situation of products. Reflected in this way, investors can have an immersive feeling and invest in their products. Second, according to the type of products developed by the fundraiser, the fundraiser should try to allow the customer to have a better sensory experience before the product is obtained, so that investors can invest in the product. For example, when the product is an experience product, for the crowdfunding promoters, in view of the background situational clues of many crowdfunding new products, the promotion of new products is common and the consumers will have different background situational clues. The degree of awakening of the mental imagery, the intention to purchase and the investment behavior that affect the new product. Therefore, sponsors should use situational cues to enhance the consumer's perception of pre-experience and investment intention in new products. Finally, this article uses the situational clues in the picture to let investors be there, virtual experience products, and whether there are other better ways to let consumers feel the products, such as story descriptions, videos, etc., which is also the future research. How to make consumers or investors better virtualize the direction of the product.

\section{REFERENCES}

[1] Wumei Liu, Jiangping Liang. To choose red or blue? Investigating whether, when and why background colors will affect visually new product evalutions [J]. Nankai Business Review, 2015, 18(5):23-35. (In Chinese)

[2] Ke Zhong. Sensory marketing power -- how five senses affect customer purchase[M].Shanghai: Shanghai People Press, 2016.(In Chinese)

[3] Jinglei Su, Chengyue Yin, Shuai Guo. The effects of online product presentation's sensory cues on consumer's purchase intention: a mental imagery perspective[J].Journal of Marketing Science, 2016, 12 (2): 87-99.(In Chinese)

[4] Macinnis D J, Price L L. The Role of Imagery in Information Processing Review and Extensions [J]. Journal of Consumer Research, 1987, 13(4):473-491.

[5] Walters G, Sparks B, Herington C. The effectiveness of print advertising stimuli in evoking elaborate consumption visions for potential travelers [J]. Journal of Travel Research, 2007, 46(1):24-34.

[6] Yoo J, Kim M. The effects of online product presentation on consumer responses: A mental imagery perspective [J]. Journal of Business Research, 2014, 67(11):2464-2472.

[7] Guowei Zhu, Yali Wu. Study on the influence of presentation upon consumer haptic perception under network environment [J].China Soft Science, 2015 (2): 146-154.(In Chinese)

[8] Jing Huang, Yupeng Zou, Hongliang Liu, Jintang Wang. The impact of online product static and dynamic presentation on consumer product evaluation[J].Chinese Journal of Management,2017, 14(5):742-750.(In Chinese)

[9] Marks D F. Visual imagery differences in the recall of pictures [J]. British Journal of Psychology, 1973, 64(1):17-24 